\title{
PERBAIKAN METODE KERJA PENGANTONGAN SEMEN MENGGUNAKAN PETA TANGAN KIRI DAN KANAN
}

\author{
Cut Ita Erliana ${ }^{1}$, Listiani Nurul Huda ${ }^{2}$, A. Rahim Matondang ${ }^{2}$ \\ ${ }^{1}$ Program Studi Teknik Industri Universitas Malikussaleh Aceh, \\ ${ }^{2}$ Program Studi Teknik Industri Universitas Sumatera Utara Medan \\ cutitha@gmail.com
}

\begin{abstract}
ABSTRAK
PT. X merupakan perusahaan yang bergerak dibidang jasa pengantongan semen dan produk yang dihasilkan adalah Semen Portland Pozzolan $50 \mathrm{~kg}$. Masalah yang dihadapi perusahaan adalah kemampuan produksi semen yang lebih rendah dari permintaan semen. Analisis dilakukan terhadap komponen sistem kerja yaitu manusia, bahan baku, mesin, dan lingkungan kerja. Hasil analisis menunjukkan bahwa faktor manusia yaitu pada metode kerja yang berpengaruh terhadap kemampuan produksi semen. Tujuan dari penelitian ini adalah mendapatkan rancangan perbaikan metode kerja pada stasiun pengantongan semen agar waktu pengerjaan produk menjadi lebih singkat sehingga jumlah produksi semen meningkat. Rancangan perbaikan metode kerja dilakukan melalui Peta Tangan Kiri dan Tangan kanan agar sesuai Prinsip Ekonomi Gerakan. Penerapan Peta Tangan Kiri dan Kanan usulan pada stasiun pengantongan semen menghasilkan penurunan waktu siklus sebesar 3,2 detik atau 44\% dan kenaikan jumlah produksi sebanyak 16,8 ton/operator.
\end{abstract}

Kata kunci : Metode Kerja, Peta Tangan Kiri dan Kanan.

\section{PENDAHULUAN}

Industri semen merupakan industri strategis yang dibutuhkan untuk pembangunan fisik berupa sarana dan prasana infrastruktur yang kebutuhannya semakin meningkat sejalan dengan meningkatnya kegiatan ekonomi masyarakat dan pembangunan nasional. Ketersediaan semen sebagai bahan untuk pembangunan merupakan kunci kelancaran roda pembangunan secara fisik yang sangat dibutuhkan guna mendukung pertumbuhan ekonomi nasional. Industri semen di Indonesia dari tahun ke tahun mengalami pertumbuhan, baik dari segi jumlah pabrik, kapasitas, maupun produksi.

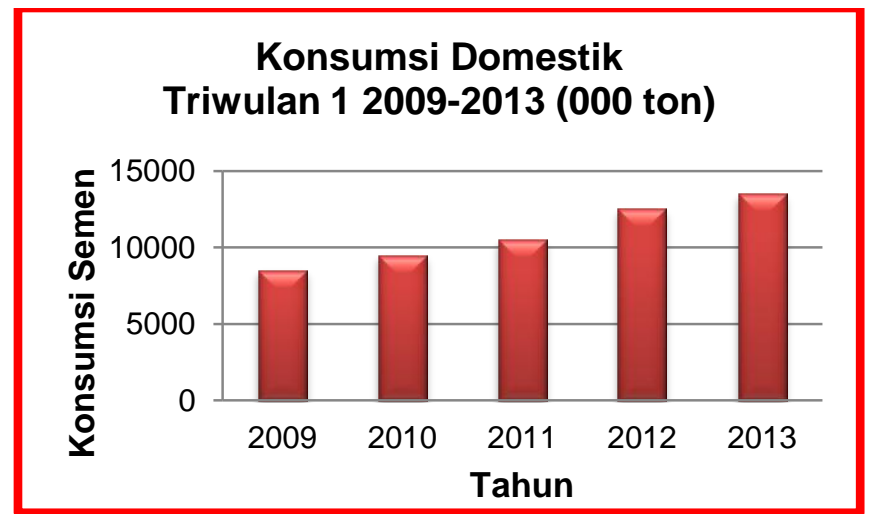

Gambar 1. Konsumsi Semen Indonesia Triwulan I Tahun 2009-2013.

Sumber: Asosiasi Semen Indonesia.

Gambar 1 menunjukkan konsumsi semen semakin meningkat tiap tahunnya. Hal ini tentu saja merupakan peluang sekaligus tantangan bagi para produsen semen dalam negeri. Para produsen semen di dalam negeri harus dapat memenuhi kebutuhan pasar dengan meningkatkan kapasitas serta kemampuan produksinya agar produktivitas selalu 
meningkat. Peningkatan kapasitas produksi dapat dilakukan salah satunya dengan penerapan metode kerja yang efektif dan efisien.

\section{LANDASAN TEORI}

\section{A. Peta Kerja}

Peta kerja adalah suatu alat yang menggambarkan kegiatan kerja secara sistematis dan jelas. Melalui peta kerja kita dapat melihat semua langkah atau proses yang dialami oleh suatu benda kerja kemudian menggambarkan semua langkah yang dialami benda kerja, seperti: transportasi, operasi mesin, pemeriksaan, perakitan, sampai akhirnya menjadi produk jadi. Apabila kita ingin melakukan studi yang seksama terhadap suatu peta kerja, maka pekerjaan kita dalam usaha memperbaiki metode kerja dari suatu proses produksi akan lebih mudah dilaksanakan. Pada dasarnya semua perbaikan tersebut ditujukan untuk mengurangi biaya produksi secara keseluruhan, dengan demikian peta ini merupakan alat yang baik untuk menganalisa suatu pekerjaan sehingga mempermudah perencanaan perbaikan kerja.

\section{B. Peta Tangan Kiri dan Tangan Kanan}

Peta tangan kiri dan kanan adalah peta kerja setempat yang bermanfaat untuk menganalisa gerakan tangan manusia didalam melakukan pekerjaan-pekerjaan yang bersifat manual. Peta ini akan menggambarkan semua gerakan ataupun delay yang terjadi yang dilakukan oleh tangan kanan maupun tangan kiri secara mendetail sesuai dengan elemen-elemen Therblig yang membentuk gerakan. Dengan menganalisa detail gerakan yang terjadi maka langkah perbaikan dapat diusulkan. Peta ini tepat digunakan untuk menganalisa gerakan yang terjadi secara berulang (repetitive motion) dan dilakukan secara manual. Berdasarkan analisa yang dilakukan maka pola gerakan tangan yang dianggap tidak efisien dan bertentangan dengan prinsip-prinsip ekonomi gerakan bisa diusulkan untuk perbaikan. Demikian pula akan diharapkan terjadi keseimbangan gerakan yang dilakukan oleh tangan kanan dan tangan kiri, sehingga siklus kerja akan berlangsung dengan lancar dalam ritme gerakan yang lebih baik yang akhirnya mampu memberikan delays maupun operator fatigue yang minimum.

\section{Prinsip Ekonomi Gerakan}

Di dalam menganalisa dan mengevaluasi metode kerja untuk memperoleh metode kerja yang lebih efisien, maka perlu mempertimbangkan prinsip-prinsip ekonomi gerakan. Prinsip ekonomi gerakan ini dapat dipergunakan untuk menganalisa gerakangerakan kerja setempat yang terjadi dalam sebuah proses kerja dan juga untuk kegiatan kerja yang berlangsung secara menyeluruh dari satu proses ke proses kerja yang lainnya. (Lawrence, 2000: 117).

1. Prinsip ekonomi gerakan dihubungkan dengan penggunaan anggota tubuh manusia:

a. Sebaiknya kedua tangan harus memulai dan mengakhiri gerakannya dalam waktu yang bersamaan.

b. Kedua tangan sebaiknya tidak menganggur pada saat yang sama kecuali pada waktu istirahat.

c. Gerakan tangan akan lebih mudah jika satu terhadap lainnya simetris dan berlawanan arah.

d. Gerakan tangan atau badan sebaiknya dihemat, yaitu hanya menggerakkan bagian badan yang diperlukan saja untuk melakukan pekerjaan dengan sebaikbaiknya.

e. Hindari gerakan yang menyebabkan perubahan arah karena akan menghabiskan waktu yang lebih banyak.

f. Pekerjaan harus diatur sedemikian rupa sehingga gerak mata terbatas pada satu bidang tanpa perlu mengubah fokus.

2. Prinsip ekonomi gerakan dihubungkan dengan tempat kerja berlangsung:

a. Sebaiknya badan dan peralatan mempunyai tempat yang tetap. 
b. Tempatkan bahan-bahan dan fasilitas kerja ditempat yang mudah dan cepat untuk dicapai.

c. Tempat penyimpanan bahan yang akan dikerjakan sebaiknya memanfaatkan prinsip gaya berat sehingga bahan yang akan dipakai selalu tersedia di tempat yang dekat untuk diambil.

d. Mekanisme yang baik untuk menyalurkan objek yang sudah selesai dirancang.

e. Bahan-bahan dan peralatan sebaiknya ditempatkan teratur sedemikian rupa sehingga gerakan-gerakan dapat dilakukan dengan urutan terbaik.

f. Tinggi tempat kerja dan kursi sebaiknya dirancang sedemikian rupa sehingga alternatif berdiri atau duduk dalam menghadapi pekerjaan merupakan suatu hal yang menyenangkan.

g. Tipe tinggi kursi harus dirancang sedemikian rupa sehingga yang mendudukinya memiliki postur yang baik dan nyaman.

h. Tata letak fasilitas kerja sebaiknya diatur sedemikian rupa sehingga dapat membentuk kondisi kerja yang baik.

3. Prinsip ekonomi gerakan dihubungkan dengan desain peralatan kerja yang dipergunakan:

a. Sebaiknya tangan dapat dibebaskan dari semua pekerjaan bila penggunaan dari perkakas pembantu atau alat yang dapat digerakan dengan kaki dapat ditingkatkan.

b. Sebaiknya peralatan dirancang sedemikian rupa agar mempunyai lebih dari satu kegunaan.

c. Peralatan sebaiknya dirancang sedemikian rupa sehingga memudahkan dalam pemegangan dan penyimpanan.

Bila setiap jari tangan melakukan gerakan sendiri-sendiri, misalnya seperti pekerjaan mengetik, beban yang didistribusikan pada jari harus sesuai dengan kekuatan masing-masing jari.

\section{METODOLOGI PENELITIAN}

A. Lokasi Penelitian

Penelitian dilaksanakan di perusahaan pengantongan semen yang berlokasi di Aceh

B. Subyek Penelitian

Subyek Penelitian adalah operator pengantongan semen yang sudah berpengalaman 8 tahun dibidangnya.

\section{Prosedur Penelitian}

Pengamatan dilakukan terhadap gerakan yang dilakukan operator pada saat pengantongan semen. Gerakan operator direkam menggunakan video camcorder sehingga pengamatan bisa lebih terperinci dan dapat diamati berulang kali.

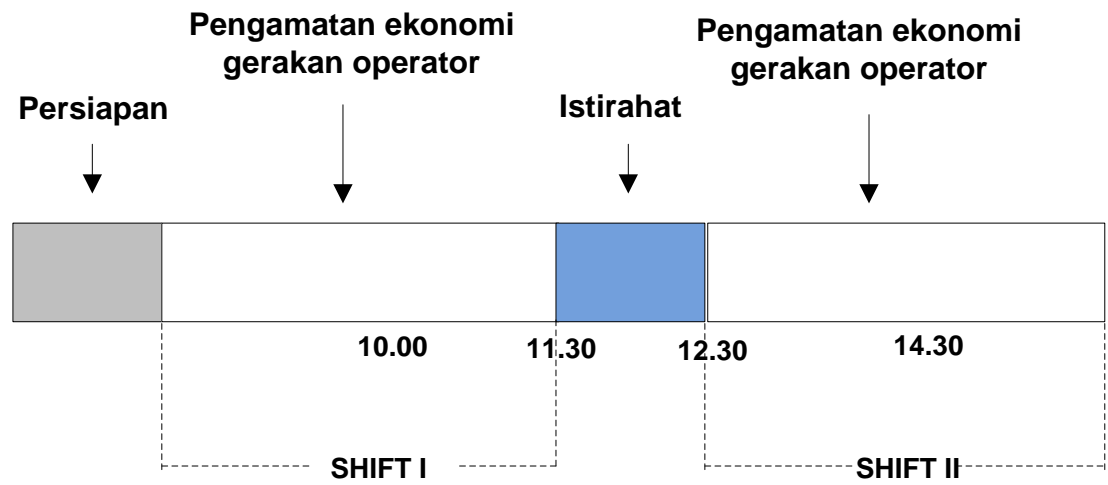

Gambar 2. Prosedur Pengamatan Gerakan Operator 


\section{HASIL DAN PEMBAHASAN}

Berdasarkan data yang diperoleh dari perusahaan, permintaan dan produksi semen tahun 2013 mengalami fluktuasi namun jumlah permintaan melebihi dari jumlah produksi. Fluktuasi ditunjukkan pada Gambar 3.

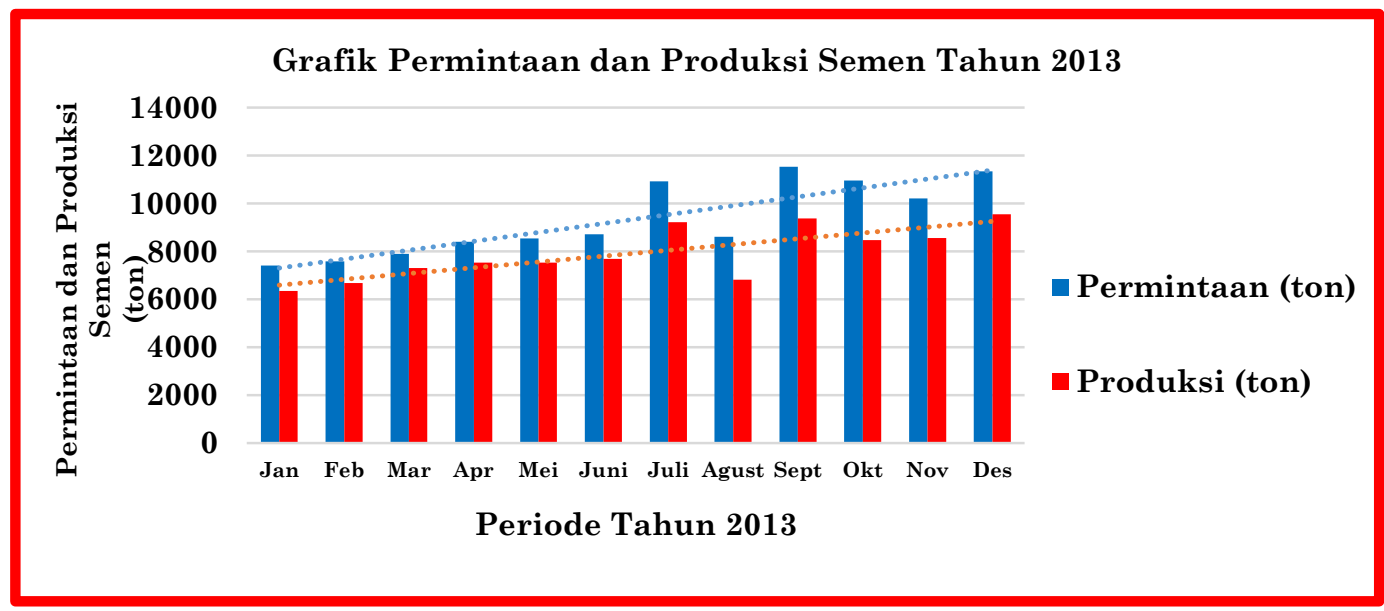

Gambar 3. Grafik Permintaan dan Produksi Semen Tahun 2013

Gambar 3 menunjukkan bahwa jumlah permintaan dan produksi semen bulan Januari sampai dengan Juli mengalami kenaikan. Pada bulan Agustus terjadi penurunan karena minimnya proyek kontruksi bertepatan dengan Bulan Ramadhan. Namun pada bulan September sampai dengan Desember jumlah permintaan dan produksi semen kembali meningkat. Secara umum, permintaan semen pada tahun 2013 terus mengalami peningkatan.

Selama ini perusahaan belum mampu memenuhi permintaan pada jam kerja, untuk memenuhi jumlah permintaan maka perusahaan menerapkan jam lembur, seperti ditunjukkan pada Gambar 4.

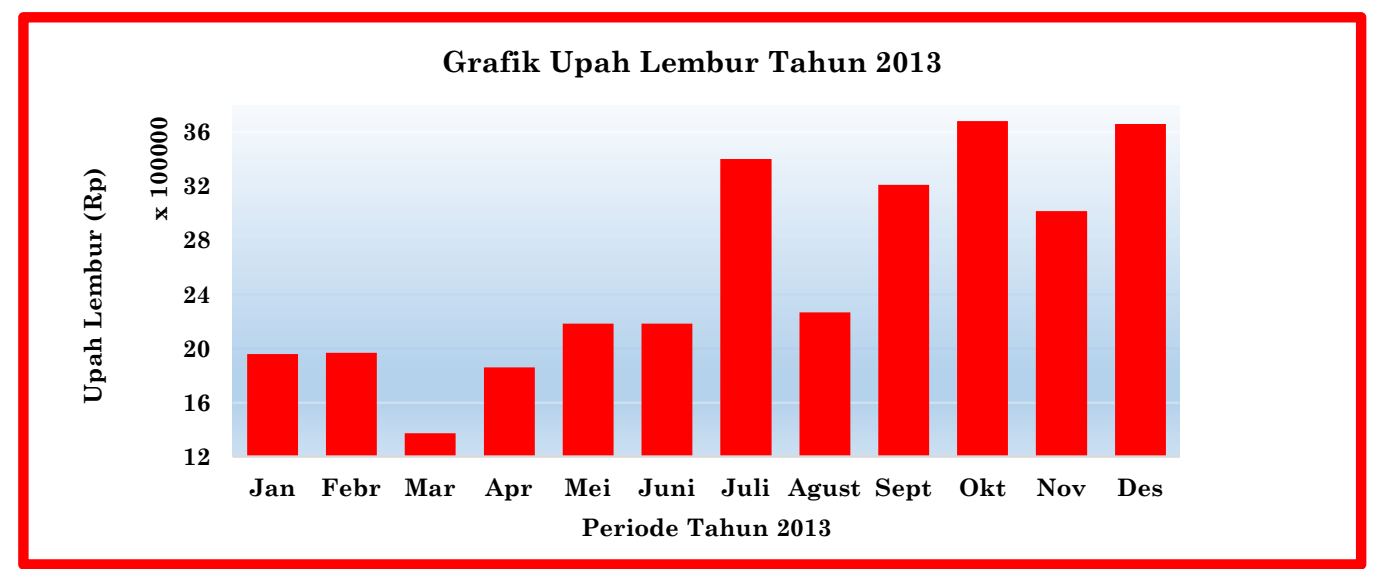

Gambar 4. Grafik Upah Lembur Tahun 2013

Gambar 4 menunjukkan bahwa upah lembur yang dikeluarkan perusahaan tiap bulan bervariasi, upah lembur tertinggi terjadi pada bulan Oktober yaitu sebesar Rp. 3.680.000,00. Hal ini disebabkan semakin banyak proyek konstruksi yang dilaksanakan 
pada akhir tahun sehingga permintaan terhadap semen meningkat. Total upah lembur tahun 2013 yang harus dibayarkan perusahaan adalah Rp.30.767.850.

Perusahaan ingin mereduksi jam lembur karena pelaksanaan lembur menambah biaya operasional perusahaan, untuk membantu perusahaan menyelesaikan masalah ini peneliti menganalisa metode kerja yang berlangsung saat ini terutama gerakan kerja yang dilakukan operator. Peneliti ingin mengetahui apakah gerakan kerja yang dilakukan operator telah memenuhi Prinsip Ekonomi Gerakan. Analisa metode kerja menggunakan peta kerja yaitu peta tangan kiri dan kanan serta peta pekerja dan mesin.

Berdasarkan pengamatan terhadap operator pengantongan semen diperoleh elemen gerakan kerja yang dilakukan operator dan ditunjukkan pada tabel 1.

Tabel 1. Elemen Gerakan Operator

\begin{tabular}{|c|c|c|}
\hline No & Pekerjaan & Elemen Gerakan \\
\hline 1 & \multirow{8}{*}{$\begin{array}{l}\text { Pengantongan } \\
\text { Semen }\end{array}$} & Menyalakan mesin packer \\
\hline \multirow{2}{*}{2} & & Berputar \\
\hline & & Berjalan ke belakang \\
\hline 3 & & Mengambil kantong semen \\
\hline \multirow{2}{*}{4} & & Berputar \\
\hline & & Berjalan ke depan memegang kantong \\
\hline 5 & & Meletakkan kantong pada lengan mesin packer \\
\hline 6 & & Berdiri (menunggu kantong semen terisi penuh) \\
\hline
\end{tabular}

Tabel 1 menunjukkan elemen gerakan yang dilakukan operator pada proses pengantongan semen. Pengantongan semen dimulai dengan gerakan menyalakan mesin packer sampai dengan meletakkan kantong semen pada lengan mesin packer dan operator menunggu kantong semen terisi penuh, demikian seterusnya.

Setelah elemen gerakan kerja operator diketahui maka dilakukan pengamatan terhadap gerakan tangan kiri dan kanan operator untuk mengetahui kesesuaian yang dilakukan tangan kiri dan kanan operator dengan prinsip ekonomi gerakan. Pemetaan dilakukan terhadap 8 operator yang sudah berpengalaman kerja dibidang pengantongan semen. Hasil pemetaan ditunjukkan pada tabel 2 s.d tabel 9. 
Tabel 2. Peta Tangan Kiri dan Tangan Kanan Operator 1

\begin{tabular}{|c|c|c|c|c|c|}
\hline \multicolumn{6}{|c|}{ PETA TANGAN KIRI DAN TANGAN KANAN } \\
\hline \multicolumn{2}{|c|}{ PEKERJAAN } & \multicolumn{4}{|c|}{ : PENGANTONGAN SEMEN } \\
\hline \multicolumn{6}{|c|}{ OPERATOR } \\
\hline \multicolumn{6}{|c|}{ NOMOR PETA } \\
\hline \multicolumn{6}{|c|}{ SEKARANG } \\
\hline \multicolumn{6}{|c|}{ DIPETAKAN OLEH } \\
\hline \multicolumn{6}{|c|}{ TANGGAL DIPETAKAN } \\
\hline TANGAN KIRI & $\begin{array}{l}\text { JARAK } \\
(\mathrm{CM})\end{array}$ & $\begin{array}{l}\text { WAKTU } \\
\text { (DET) }\end{array}$ & $\begin{array}{l}\text { WAKTU } \\
\text { (DET) }\end{array}$ & \begin{tabular}{|c} 
JARAK \\
$(\mathrm{CM})$
\end{tabular} & $\begin{array}{l}\text { TANGAN } \\
\text { KANAN }\end{array}$ \\
\hline Menunggu & 0 & 1,5 & 1,5 & 30 & Menyalakan \\
\hline Menunggu & 0 & 1,6 & \multirow[b]{2}{*}{2,6} & \multirow[b]{2}{*}{20} & \multirow{2}{*}{$\begin{array}{c}\text { Mengambil } \\
\text { kantong semen }\end{array}$} \\
\hline $\begin{array}{c}\text { Menahan tumpukan } \\
\text { kantong semen }\end{array}$ & 20 & 1 & & & \\
\hline Menunggu & 0 & 1 & \multirow[b]{2}{*}{2,1} & \multirow[b]{2}{*}{0} & \multirow{2}{*}{$\begin{array}{l}\text { Memegang } \\
\text { kantong semen }\end{array}$} \\
\hline $\begin{array}{c}\text { Merapikan bawah } \\
\text { kantong semen }\end{array}$ & 0 & 1,1 & & & \\
\hline Menunggu & 0 & 1 & 1 & 40 & $\begin{array}{c}\text { Meletakkan } \\
\text { kantong semen } \\
\text { di mesin }\end{array}$ \\
\hline Total & 20 & 7,2 & 7,2 & 90 & \\
\hline
\end{tabular}

Peta tangan kiri dan tangan kanan pada Tabel 1 menunjukkan bahwa terdapat 4 gerakan menunggu pada tangan kiri dan tidak terdapat kegiatan menunggu pada tangan kanan. Kedua tangan tidak memulai dan mengakhiri gerakannya dalam waktu yang bersamaan. Hal ini menunjukkan adanya ketidakseimbangan beban kerja antara tangan kiri dan tangan kanan pada operator 1.

Tabel 3. Peta Tangan Kiri dan Tangan Kanan Operator 2

\begin{tabular}{|c|c|c|c|c|c|}
\hline \multicolumn{6}{|c|}{ PETA TANGAN KIRI DAN TANGAN KANAN } \\
\hline \multicolumn{3}{|c|}{ PEKERJAAN } & \multicolumn{3}{|c|}{ : PENGANTONGAN SEMEN } \\
\hline \multicolumn{4}{|c|}{ OPERATOR } & \multicolumn{2}{|c|}{$\begin{array}{l}\text { TONGAN SEMEN } \\
: 2\end{array}$} \\
\hline \multicolumn{4}{|c|}{ NOMOR PETA } & \multicolumn{2}{|l|}{02} \\
\hline \multicolumn{4}{|c|}{ SEKARANG } & \multicolumn{2}{|l|}{$: \sqrt{ }$} \\
\hline \multicolumn{4}{|c|}{ DIPETAKAN OLEH } & \multicolumn{2}{|l|}{ CUT ITA } \\
\hline \multicolumn{6}{|c|}{ TANGGAL DIPETAKAN } \\
\hline TANGAN KIRI & $\begin{array}{l}\text { JARAK } \\
(\mathrm{CM})\end{array}$ & $\begin{array}{l}\text { WAKTU } \\
\text { (DET) }\end{array}$ & $\begin{array}{l}\text { WAKTU } \\
\text { (DET) }\end{array}$ & $\begin{array}{l}\text { JARAK } \\
(\mathrm{CM})\end{array}$ & $\begin{array}{l}\text { TANGAN } \\
\text { KANAN }\end{array}$ \\
\hline Memegang & 30 & 1,5 & 1,5 & 30 & Menyalakan mesin \\
\hline Menunggu & 0 & 2,7 & 2,7 & 20 & $\begin{array}{c}\text { Mengambil } \\
\text { kantong semen }\end{array}$ \\
\hline Menunggu & 0 & 2,1 & 2,1 & 0 & $\begin{array}{l}\text { Memegang kantong } \\
\text { semen }\end{array}$ \\
\hline Menunggu & 0 & 1 & 1 & 40 & $\begin{array}{c}\text { Meletakkan } \\
\text { kantong semen di }\end{array}$ \\
\hline Total & 30 & 7,3 & 7,3 & 90 & \\
\hline
\end{tabular}

Peta tangan kiri dan tangan kanan pada Tabel 2 menunjukkan bahwa terdapat 3 gerakan menunggu pada tangan kiri dan tidak terdapat kegiatan menunggu pada tangan kanan. Tangan kiri dan kanan operator tidak mengakhiri gerakannya dalam waktu yang 
bersamaan. Hal ini juga menunjukkan adanya ketidakseimbangan beban kerja antara tangan kiri dan tangan kanan pada operator 2.

Tabel 4. Peta Tangan Kiri dan Tangan Kanan Operator 3

\begin{tabular}{|c|c|c|c|c|c|}
\hline \multicolumn{6}{|c|}{ PETA TANGAN KIRI DAN TANGAN KANAN } \\
\hline \multicolumn{3}{|c|}{ PEKERJAAN } & \multicolumn{3}{|c|}{ PENGANTONGAN SEMEN } \\
\hline \multicolumn{4}{|c|}{ OPERATOR } & \multicolumn{2}{|c|}{$\begin{array}{l}\text { TONGAN SEMEN } \\
: 3\end{array}$} \\
\hline \multicolumn{6}{|c|}{ NOMOR PETA } \\
\hline \multicolumn{6}{|c|}{ SEKARANG } \\
\hline \multicolumn{6}{|c|}{ DIPETAKAN OLEH } \\
\hline \multicolumn{6}{|c|}{ TANGGAL DIPETAKAN } \\
\hline TANGAN KIRI & $\begin{array}{l}\text { JARAK } \\
(\mathrm{CM})\end{array}$ & $\begin{array}{l}\text { WAKTU } \\
\text { (DET) }\end{array}$ & $\begin{array}{l}\text { WAKTU } \\
\text { (DET) }\end{array}$ & $\begin{array}{l}\text { JARAK } \\
(\mathrm{CM})\end{array}$ & TANGAN KANAN \\
\hline Menunggu & 0 & 1,5 & 1,5 & 30 & Menyalakan mesin \\
\hline Menunggu & 0 & 2,8 & 2,8 & 20 & $\begin{array}{c}\text { Mengambil kantong } \\
\text { semen }\end{array}$ \\
\hline $\begin{array}{l}\text { Memegang kantong } \\
\text { semen }\end{array}$ & 0 & 2,2 & 2,2 & 0 & $\begin{array}{l}\text { Memegang kantong } \\
\text { semen }\end{array}$ \\
\hline Menunggu & 0 & 1 & 1 & 40 & $\begin{array}{c}\text { Meletakkan kantong } \\
\text { semen di mesin }\end{array}$ \\
\hline Total & 0 & 7,5 & 7,5 & 90 & \\
\hline
\end{tabular}

Tabel 5. Peta Tangan Kiri dan Tangan Kanan Operator 4

\begin{tabular}{|c|c|c|c|c|c|}
\hline \multicolumn{7}{|c|}{ PETA TANGAN KIRI DAN TANGAN KANAN } \\
\hline \multicolumn{7}{|c|}{ OPERATOR } & $: 4$ \\
\hline PEKERJAAN PENGANTONGAN SEMEN \\
\hline \multicolumn{7}{|c|}{ SEKARANG } & $: 04$ \\
\hline DIPETAKAN OLEH & $: \sqrt{ }$ \\
\hline \multicolumn{7}{|c|}{ TANGT ITA } \\
\hline TANGAN KIRI & $\begin{array}{c}\text { JARAK } \\
\text { (CM) }\end{array}$ & $\begin{array}{c}\text { WAKTU } \\
\text { (DET) }\end{array}$ & $\begin{array}{c}\text { WAKTU } \\
\text { (DET) }\end{array}$ & $\begin{array}{c}\text { JARAK } \\
(\mathrm{CM})\end{array}$ & TANGAN KANAN \\
\hline Menunggu & 0 & 1,5 & 1,5 & 30 & Menyalakan mesin \\
\hline Menunggu & 0 & 2,5 & 2,5 & 20 & Mengambil kantong \\
\hline Memegang kantong & 0 & 2 & 2 & 0 & Memegang kantong \\
\hline Menunggu & 0 & 1,5 & 1,5 & 40 & Meletakkan kantong \\
\hline Total & 0 & 7,5 & 7,5 & 90 & \\
\hline
\end{tabular}


Tabel 6. Peta Tangan Kiri dan Tangan Kanan Operator 5

\begin{tabular}{|c|c|c|c|c|c|}
\hline \multicolumn{8}{|c|}{ PETA TANGAN KIRI DAN TANGAN KANAN } \\
\hline \multicolumn{7}{|c|}{ OPERATOR } & $:$ PENGANTONGAN SEMEN \\
\hline PEMOR PETA & $: 05$ \\
\hline \multicolumn{7}{|c|}{ DEKARANG } & $: \sqrt{ }$ \\
\hline \multicolumn{7}{|c|}{ TANGTAKAN OLEH } & $:$ CUT ITA \\
\hline JARA & WAKT & WAKT & JARA & TANGAN KANAN \\
\hline TANGAN KIRI & K (CM) & U (DET) & U (DET) & K (CM) & Menyalakan mesin \\
\hline Menunggu & 0 & 1,5 & 1,5 & 30 & Mengambil kantong semen \\
\hline Memegang meja & 20 & 2,8 & 2,8 & 20 & Memegang kantong semen \\
\hline Memegang kantong & 0 & 2 & 2 & 0 & di mesin \\
\hline Menunggu & 0 & 1 & 1 & 40 & Meletakkan kantong semen \\
\hline Total & 20 & 7,3 & 7,3 & 90 & \\
\hline
\end{tabular}

Tabel 7. Peta Tangan Kiri dan Tangan Kanan Operator 6

\begin{tabular}{|c|c|c|c|c|c|}
\hline \multicolumn{6}{|c|}{ PETA TANGAN KIRI DAN TANGAN KANAN } \\
\hline \multicolumn{3}{|c|}{ PEKERJAAN } & \multicolumn{3}{|c|}{ : PENGANTONGAN SEMEN } \\
\hline \multicolumn{4}{|c|}{ OPERATOR } & \multicolumn{2}{|c|}{$: 6$} \\
\hline \multicolumn{6}{|c|}{ NOMOR PETA } \\
\hline \multicolumn{6}{|c|}{ SEKARANG } \\
\hline \multicolumn{6}{|c|}{ DIPETAKAN OLEH } \\
\hline \multicolumn{6}{|c|}{ TANGGAL DIPETAKAN } \\
\hline TANGAN KIRI & $\begin{array}{c}\text { JARA } \\
\mathrm{K}(\mathrm{CM})\end{array}$ & $\begin{array}{l}\text { WAKT } \\
\text { U (DET) }\end{array}$ & $\begin{array}{l}\text { WAKT } \\
\text { U (DET) }\end{array}$ & $\begin{array}{c}\text { JARA } \\
\mathrm{K}(\mathrm{CM})\end{array}$ & TANGAN KANAN \\
\hline Menunggu & 0 & 1,5 & 1,5 & 30 & Menyalakan mesin \\
\hline Memegang meja & 20 & 2,7 & 2,7 & 20 & Mengambil kantong semen \\
\hline Menunggu & 0 & 2 & 2 & 0 & Memegang kantong semen \\
\hline Menunggu & 0 & 1 & 1 & 40 & $\begin{array}{l}\text { Meletakkan kantong semen } \\
\text { di mesin }\end{array}$ \\
\hline Total & 20 & 7,2 & 7,2 & 90 & \\
\hline
\end{tabular}


Tabel 8. Peta Tangan Kiri dan Tangan Kanan Operator 7

\begin{tabular}{|c|c|c|c|c|c|}
\hline \multicolumn{6}{|c|}{ PETA TANGAN KIRI DAN TANGAN KANAN } \\
\hline \multicolumn{3}{|c|}{ PEKERJAAN } & \multicolumn{3}{|c|}{ PENGANTONGAN SEMEN } \\
\hline \multicolumn{4}{|c|}{ OPERATOR } & \multicolumn{2}{|c|}{$\begin{array}{l}\text { ONGAN SEMEN } \\
: 7\end{array}$} \\
\hline \multicolumn{6}{|c|}{ NOMOR PETA } \\
\hline \multicolumn{6}{|c|}{ SEKARANG } \\
\hline \multicolumn{6}{|c|}{ DIPETAKAN OLEH } \\
\hline \multicolumn{6}{|c|}{ TANGGAL DIPETAKAN } \\
\hline TANGAN KIRI & $\begin{array}{l}\text { JARAK } \\
(\mathrm{CM})\end{array}$ & $\begin{array}{l}\text { WAKTU } \\
\text { (DET) }\end{array}$ & $\begin{array}{l}\text { WAKTU } \\
\text { (DET) }\end{array}$ & \begin{tabular}{|c} 
JARAK \\
$(\mathrm{CM})$
\end{tabular} & TANGAN KANAN \\
\hline Menyalakan mesin & 30 & 1,5 & 1,5 & 0 & Menunggu \\
\hline $\begin{array}{l}\text { Mengambil kantong } \\
\text { semen }\end{array}$ & 20 & 2,6 & 2,6 & 0 & Menunggu \\
\hline $\begin{array}{c}\text { Memegang kantong } \\
\text { semen }\end{array}$ & 0 & 1,9 & 1,9 & 0 & Menunggu \\
\hline $\begin{array}{l}\text { Meletakkan kantong } \\
\text { semen di mesin }\end{array}$ & 40 & 1,3 & 1,3 & 0 & Menunggu \\
\hline Total & 90 & 7,3 & 7,3 & 0 & \\
\hline
\end{tabular}

Tabel 9. Peta Tangan Kiri dan Tangan Kanan Operator 8

\begin{tabular}{|c|c|c|c|c|c|}
\hline \multicolumn{6}{|c|}{ PETA TANGAN KIRI DAN TANGAN KANAN } \\
\hline \multicolumn{3}{|c|}{ PEKERJAAN } & \multicolumn{3}{|c|}{ : PENGANTONGAN SEMEN } \\
\hline \multicolumn{4}{|c|}{ OPERATOR } & \multicolumn{2}{|c|}{$: 8$} \\
\hline \multicolumn{4}{|c|}{ NOMOR PETA } & \multicolumn{2}{|l|}{$: 08$} \\
\hline \multicolumn{4}{|c|}{ SEKARANG } & \multicolumn{2}{|l|}{$: \sqrt{ }$} \\
\hline \multicolumn{4}{|c|}{ DIPETAKAN OLEH } & \multicolumn{2}{|c|}{ : CUT ITA } \\
\hline \multicolumn{4}{|c|}{ TANGGAL DIPETAKAN } & \multicolumn{2}{|c|}{16 JUNI 2014} \\
\hline TANGAN KIRI & $\begin{array}{c}\text { JARAK } \\
(\mathrm{CM})\end{array}$ & $\begin{array}{l}\text { WAKTU } \\
\text { (DET) }\end{array}$ & $\begin{array}{c}\text { WAKTU } \\
\text { (DET) }\end{array}$ & $\begin{array}{l}\text { JARAK } \\
(\mathrm{CM})\end{array}$ & TANGAN KANAN \\
\hline Memegang mesin & 30 & 1,5 & 1,5 & 30 & Menyalakan mesin \\
\hline Menunggu & 0 & 2,7 & 2,6 & 20 & Mengambil kantong \\
\hline Menunggu & 0 & 2,1 & 2,1 & 0 & Memegang kantong \\
\hline Menunggu & 0 & 1 & 1 & 40 & $\begin{array}{l}\text { Meletakkan kantong } \\
\text { semen di mesin }\end{array}$ \\
\hline Total & 30 & 7,2 & 7,2 & 90 & \\
\hline
\end{tabular}

Peta tangan kiri dan tangan kanan pada Tabel 3 s.d Tabel 9 menunjukkan bahwa frekuensi gerakan menunggu lebih sering dilakukan oleh tangan kiri. Dengan demikian berdasarkan hasil pemetaan tangan kiri dan kanan pada operator 1 sampai dengan operator 8 menunjukkan adanya ketidakseimbangan beban kerja antara tangan kiri dan tangan kanan. 
Tabel 10. Rekapitulasi Waktu Gerakan Tangan Operator 1 s.d 8

\begin{tabular}{|c|c|c|}
\hline \multirow{2}{*}{ Operator } & \multicolumn{2}{|c|}{ Waktu Gerakan (det) } \\
\cline { 2 - 3 } & Tangan Kiri (det) & Tangan Kanan \\
\hline Operator 1 & 2,1 & 7,2 \\
\hline Operator 2 & 1,5 & 7,3 \\
\hline Operator 3 & 2,2 & 7,5 \\
\hline Operator 4 & 2 & 7,5 \\
\hline Operator 5 & 4,8 & 7,3 \\
\hline Operator 6 & 2,7 & 7,2 \\
\hline Operator 7 & 0 & 7,3 \\
\hline Operator 8 & 1,5 & 7,2 \\
\hline
\end{tabular}

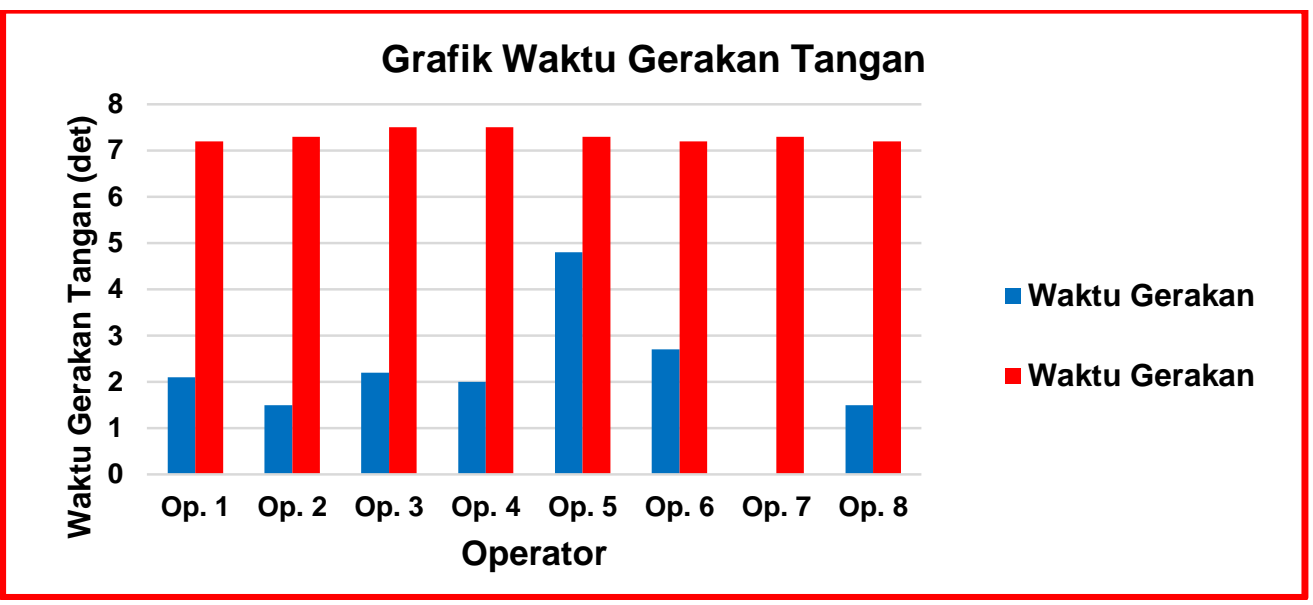

Gambar 5. Grafik Waktu Gerakan Tangan

Gambar 5 menunjukkan bahwa kecenderungan tangan kanan melakukan pekerjaan sebesar $80 \%$ dan tangan kiri sebesar 20\%. Artinya tangan kanan lebih banyak melakukan pekerjaan dibandingkan dengan tangan kiri. Pekerjaan diawali dengan tangan kanan dan diakhiri dengan tangan kanan. Hal ini tidak sesuai dengan prinsip ekonomi gerakan.

\section{Aspek Perancangan dan Perbaikan}

Berdasarkan hasil observasi, identifikasi, perumusan, dan pengukuran maka peneliti mengusulkan solusi untuk mengurangi waktu pengerjaan produk pada PT. X dengan perbaikan metode kerja tepatnya pada gerakan kerja yang tidak sesuai dengan prinsip ekonomi gerakan. Gerakan kerja operator yang tidak sesuai dengan prinsip ekonomi gerakan akan dieliminasi, dalam hal ini adalah gerakan berputar dan berjalan yang terjadi ketika operator mengambil zag semen yang kosong kemudian berputar lagi untuk meletakkan zag semen ke lengan pengisi (spout) mesin packer. Gerakan ini dieliminasi karena menimbulkan adanya perubahan arah. Gerakan kerja setelah eliminasi ditunjukkan pada tabel 11.

Tabel 11. Elemen Gerakan Operator

\begin{tabular}{|c|c|c|}
\hline No & Pekerjaan & Elemen Gerakan \\
\hline 1. & \multirow{3}{*}{$\begin{array}{c}\text { Pengantongan } \\
\text { Semen }\end{array}$} & Menyalakan mesin packer \\
2. & & Mengambil kantong semen \\
3. & & Meletakkan kantong pada lengan mesin packer \\
& & Berdiri (menunggu kantong semen terisi penuh) \\
\hline
\end{tabular}


Peta tangan kiri dan tangan kanan usulan mengacu pada gerakan usulan yang dilakukan operator dan ditunjukkan pada tabel 12.

Tabel 12. Peta Tangan Kiri dan Tangan Kanan Usulan

\begin{tabular}{|c|c|c|c|c|c|}
\hline \multicolumn{6}{|c|}{ PETA TANGAN KIRI DAN TANGAN KANAN } \\
\hline \multicolumn{3}{|c|}{ PEKERJAAN } & \multicolumn{3}{|c|}{ PENGANTONGAN SEMEN } \\
\hline \multicolumn{4}{|c|}{ OPERATOR } & \multicolumn{2}{|c|}{$\begin{array}{l}\text { ONGAN SEMEN } \\
: 1\end{array}$} \\
\hline \multicolumn{4}{|c|}{ NOMOR PETA } & \multicolumn{2}{|c|}{$: 09$} \\
\hline \multicolumn{4}{|c|}{ USULAN } & \multicolumn{2}{|l|}{$\sqrt{ }$} \\
\hline \multicolumn{4}{|c|}{ DIPETAKAN OLEH } & \multicolumn{2}{|l|}{ UT ITA } \\
\hline \multicolumn{6}{|c|}{ TANGGAL DIPETAKAN } \\
\hline TANGAN KIRI & $\begin{array}{l}\text { JARAK } \\
(\mathrm{CM})\end{array}$ & $\begin{array}{l}\text { WAKTU } \\
\text { (DET) }\end{array}$ & $\begin{array}{l}\text { WAKTU } \\
\text { (DET) }\end{array}$ & $\begin{array}{l}\text { JARAK } \\
(\mathrm{CM})\end{array}$ & TANGAN KANAN \\
\hline Menyalakan mesin & 30 & 1,5 & 1,5 & 20 & Mengambil kantong \\
\hline Menunggu & 0 & 1,5 & 1,5 & 40 & $\begin{array}{l}\text { Meletakkan kantong } \\
\text { semen pada mesin }\end{array}$ \\
\hline $\begin{array}{l}\text { Memegang kantong } \\
\text { semen }\end{array}$ & 30 & 1 & 1 & 20 & $\begin{array}{l}\text { Mengambil kantong } \\
\text { semen berikutnya }\end{array}$ \\
\hline Total & 60 & 4 & 4 & 80 & \\
\hline
\end{tabular}

Pada tabel 12 dapat diketahui bahwa Peta Tangan Kiri dan Tangan Kanan dengan gerakan kerja usulan menghasilkan waktu 4 detik. Kedua tangan operator memulai dan mengakhiri gerakan dalam waktu yang bersamaan. Hal ini telah sesuai dengan prinsip ekonomi gerakan.

\section{Perbandingan Waktu Gerakan Tangan Aktual dan Usulan}

Tabel 13. Perbandingan Waktu Gerakan Tangan

\begin{tabular}{|c|c|c|}
\hline \multirow{2}{*}{ Operator } & \multicolumn{2}{|c|}{ Waktu Gerakan (det) } \\
\cline { 2 - 3 } & Tangan Kiri (det) & Tangan Kanan \\
\hline Operator 1 & 2,1 & 7,2 \\
\hline Operator 1 & 4 & 4 \\
\hline
\end{tabular}

Gerakan tangan usulan memberikan waktu lebih singkat dibandingkan waktu gerakan tangan aktual. Perbedaan waktu yang dihasilkan adalah 3,2 detik (44\%) lebih cepat dan semen yang dihasilkan juga bertambah sehingga dengan perbaikan metode kerja diharapkan jam lembur dapat dikurangi.

Tabel 14. Perbandingan Hasil Produksi Semen

\begin{tabular}{|c|c|}
\hline Operator & Hasil (ton) \\
\hline Operator 1 shift 1 & 33,6 ton \\
\hline Operator 1 shift 2 & 50,4 ton \\
\hline
\end{tabular}

Berdasarkan Tabel 14 dapat diketahui bahwa operator dengan gerakan tangan usulan menghasilkan 16,8 ton semen lebih banyak atau meningkat sekitar 33\% dibandingkan operator yang menerapkan gerakan tangan aktual. 


\section{KESIMPULAN}

Berdasarkan analisis dari pembahasan yang telah dilakukan maka dapat disimpulkan bahwa penyebab rendahnya jumlah produksi semen adalah pada komponen manusia terutama pada metode kerja. Rancangan perbaikan metode kerja dilakukan dengan peta tangan kiri dan tangan kanan dan sesuai dengan prinsip ekonomi gerakan. Penerapan peta tangan kiri dan tangan kanan menghasilkan kedua tangan operator memulai dan mengakhiri gerakan dalam waktu yang bersamaan dan ini telah sesuai dengan prinsip ekonomi gerakan. Peta tangan kiri dan kanan usulan dapat mereduksi waktu siklus dari 7,2 detik berkurang sebesar 3,2 detik (44\%) menjadi 4 detik. Operator yang menerapkan metode kerja usulan dapat menghasilkan 16,8 ton lebih banyak dibandingkan operator yang menerapkan metode kerja aktual.

\section{DAFTAR PUSTAKA}

[1] Aft, Lawrence S. Work Measurement and Methods Improvement. Willey. NewYork. 2000.

[2] Muhundhan,M. Ergonomy for Productivity. Indian Textile Journal.May 2013 Vol.123 N0.8:57-66.

[3] Meyers, Fred E. Motion and Time Study For Lean Manufacturing Handbook. Prentice Hall. USA. 2002.

[4] V Shinde, Gurunath, dkk. Ergonomic Analysys of an Assembly Workstation to identify Time Consuming and Fatique Causing Factors Using Application of Motion Study. IJET. Vol.4 Aug-Sept 2012:220-227.

[5] Wignjosoebroto, Sritomo. Ergonomi Studi Gerak dan Waktu. Surabaya: Penerbit Guna Widya. 2008. 